Tempo Social; Rev. Sociol. USP, S. Paulo, 1(1): 227-234, 1.sem. 1989.

\title{
POR UMA GEOGRAFIA HOSPITALAR
}

José Leopoldo Ferreira Antunes*

\begin{abstract}
RESUMO: O artigo postula e anuncia uma nova disciplina - a "geografia hospitalar" - que enfoca as instituições de atenção à doença e os procedimentos profissionais de saúde. Suas bases são lançadas de modo sumário, e seu objeto de intervenção é dividido em três áreas: o estudo retrospectivo da inserção do hospital no traçado urbano, o registro da divisão interna de espaços no ambiente hospitalar e o reconhecimento dos diferentes fluxos migratórios em seu interior, e a análise da relação que entre si estabelecem hospital e sociedade. Sob o pretexto de apresentar os principais parâmetros de uma disciplina inédita, o ensaio procura sublinhar uma perspectiva nâo-convencional de abordagem das instituições médicas, e, ainda que apenas como diretriz para pesquisas, converge para a crítica desses estabelecimentos.
\end{abstract}

UNITERMOS: Instituições de saúde, hospital e urbanismo, hospital e sociedade.

Muito antes qué a medicina, a arquitetura foi a primeira arte a ocupar-se do hospital. A idéia de que o doente necessita de cuidados e abrigo é anterior à possibilidade de lhe dispensar tratamento médico. E todas as cidades, em todas as épocas, mobilizaram-se para prover esta necessidade. Templos, conventos e mosteiros foram as primei-

* Pesquisador científico do Instituto Adolfo Lutz da Secretaria de Estado da Saúde (São Paulo). Pos-graduando do Departamento de Sociologia da FFLCH-USP. 
ras instituições a recolher doentes e providenciar-lhes atenções especiais, como no culto a Asclépio na Grécia Antiga. Organizações especificamente médicas surgiram no Império Romano inspiradas por motivos econômicos e militares. Mesmo assim, toda a Idade Média partilhou a convicção de que a assistência social era o remédio mais indicado em casos de doença e outros infortúnios.

$\mathrm{O}$ que fazer com o doente? Essa questão é antiga, e tem implicaçöes coletivas e sociais desde sempre reconhecidas. Curiosas soluções foram-lhe aplicadas ao longo dos anos, todas centradas no postulado de que o doente deveria ser instalado na posição horizontal numa área de acesso restrito. Dessa maneira, os hospitais medievais foram construídos como verdadeiros labirintos onde pequenas celas, com o tamanho da cama, sucediam-se num emaranhado de corredores pelo qual circulavam os religiosos que vinham trazer conforto espiritual aos corpos doloridos. A caridade fora cultivada pelas principais religiões do Ocidente - judaísmo, cristianismo e islamismo - e, assim, toda uma classe de desprovidos não tardou a reivindicar os benefícios do recolhimento hospitalar. Além deles, também os viajantes costumavam recorrer a este expediente, contribuindo à confusão etimológica entre hospital e hospitalidade.

Associada à secularização de seu controle administrativo, a conjunção da medicina com o hospital favoreceu, num momento histórico posterior, o surgimento do hospital moderno. Louvado por uns, temido por outros, foi considerado espaço ideal para o provimento de serviços gerais de saúde à população. E experimentou intenso desenvolvimento baseado no progresso científico recente. A especialização da medicina dividiu as doenças em diferentes categorias, e separou os enfermos de acordo com esta classificação. Além disso, a complexidade crescente dos procedimentos diagnósticos e terapêuticos complicou a tal ponto o ambiente hospitalar, que hoje em dia, quem adentrasse seus corredores desavisadamente, poderia acreditar estar passeando numa dessas naves espaciais que vemos nos seriados de ficção científica.

Alçados ao topo de sua hierarquia técnica e administrativa, os médicos determinaram talvez a maior parte dessas alterações. Outras terão sido impostas pelos critérios modernos de otimização de recursos, enquanto algumas, ainda, teriam derivado de mudanças nos costumes. De qualquer modo, o hospital erigiu-se em monumental acervo de documentos que ultrapassa as necessidades de transmissão do saber médico, e o converte em lugar privilegiado da produção de conhecimentos humanos em geral. Uma nova disciplina abordando as diferentes questões espaciais envolvidas na configuração hospitalar poderia ser proposta. Seu título - geografia hospitalar - seria o índice da aspiração médica em estatuir o hospital como meio natural de perseguir fins legítimos. $\mathrm{O}$ presente artigo propōe-se, numa pretensão desmesurada, a lançar bases para a nova disciplina. 
Além dos arranha-céus, igrejas e shopping centers, um tipo de prédio chama atenção por seu porte imponente: o hospital. A instituição médica cultiva uma singularidade que a diferencia no contexto urbano, e justifica-a enquanto local aparte. Visa instalar um espaço onde fosse permitido algo que a sociedade no mais das vezes exclui - de um lado, a sobrevivência dos enfermos, de outro, a morte. As doenças dotam uma situação de certas tensões psicológicas que impedem as pessoas de cumprirem suas responsabilidades sociais. Os hospitais pretendem cumprir a função de distender esse amplo leque de preocupações que poderia emperrar a vida social. E tal despreocupação, característica urbana acentuada nas metrópoles, apenas é possível graças a um espaço próprio especialmente designado para o super-dimensionamento de uma preocupação.

Ao configurar um espaço alheio às atribulações do dia a dia, onde estão teoricamente maximizadas as condições de cuidado com a saúde, os hospitais acreditam liberar os cidadãos a seus muitos afazeres, eximindo-os de preocupações com a própria saúde e a de seus próximos. Desse modo, os cidadãos poderiam otimizar a aplicação de seu tempo nas demais esferas da vida societária - o trabalho, o lazer, as relações familiares, as amizades, etc. O funcionamento de seus corpos, assim como a educação de seus filhos, a construção de suas moradas e a confecção de suas roupas, passa a ser delegado a um segmento social especificamente qualificado. Esse processo exime as pessoas de até mesmo pensar neste assunto. Hoje enı dia, o precavido, que "pensa" na saúde, é quem não atrasa o pagamento mensal de algum tipo de seguro de saúde or consórcio médico, e não os que tentam refletir sobre as próprias reações fisiológicas.

"Vá cuidar de sua vida, que de sua saúde cuidamos nós!" dizia o anúncio de um convênio empresarial para prestação de serviços de assistência médico-hospitalar. De certa forma, captara bem o sentido da intervenção dos hospitais nas sociedades contemForâneas. A distinção idealizada entre "vida" e "saúde" reflete a segmentação da organização social, e a alienação de dimensões da existência a que estamos sujeitos. E é a outra face da exterioridade que o hospital institui com relação à vida social. Este é o principal conceito que a nova disciplina utiliza num primeiro enfoque geográfico, que akorda a inserção do hospital nas cidades. Sua percepção implica em duas conseqüências.

Por um lado, essa exterioridade apresenta vias de escape aos encargos sociais de uma vida tão perturbada por obrigações e carências, e exerce um certo fascínio, um poder de atração sobre os cidadãos. A atenção médica, uma ação sobre os corpos, poce ser pensada em uma acepção benigna, como um carinho aos despossuídos. Deste modo, a função do hospital seria conceder a bênção de um local sagrado ao qual as pessoas acorrem exigindo sua internação, mesmo que, nuitas vezes, e sem o saberem, apenas para comungar uma refeição ou uma noite dormida em leitos hospitalares.

Por outro lado, entretanto, o hospital é responsável por um poder de repulsa sobre os cidadãos, que faz eco às configurações hospitalares de outrora. O hospital superou 

Paulo, 1(1): 227-234, 1.sem. 1989.

ao longo da história inúmeras restrições da opinião pública que o tomava por lugar infecto onde a morte campeava às soltas. Além da aversão à doença e o receio de contágio, outro processo incrementava o repúdio ao hospital: a identificação dos ideais sanitários com a consciência moral que consiste e cimenta a vida urbana. Este mecanismo é responsável por uma intervenção recíproca, e faz da doença um mal, ao mesmo tempo que transforma em doença, e por extensão, em objetos da ação hospitalar, outros males morais, como o são considerados o homossexualismo, o consumo de drogas e o crime.

Este intrincado jogo de atração e repulsão faz do hospital objeto do desejo e da aversão, e suscita angústia a quem com ele se envolve. Tem como subproduto a maior dificuldade em se atribuir sentidos e decifrar os significados de tudo quanto pode ser vislumbrado em seu interior. Este processo realimenta o medo de alguns, a admiração de outros, e motiva sentimentos ambígüos em todos. A atração e a repulsão que o hospital provoca nos cidadãos serão também instrumentos do trabalho científico do geógrafo hospitalar, que estuda a incidência da instituição médica no traçado urbano.

Fenômeno típico da vida em cidade, o hospital é imprescindível mesmo àquelas de pequeno porte, e raramente é construído no campo. As exceções que confirmam a regra se inserem em projetos mais amplos de urbanização e extensão de serviços urbanos à zona rural. A proximidade necessária aos centros populosos é compensada por uma tendência secular que direciona a instalação de hospitais para os limites de jurisdição do município. É interessante notar que, recentemente, quando representantes eclesiásticos falam em financiar a construção de um hospital especializado na atenção aos pacientes com AIDS, lembrem-se também de mencionar que ele deveria ser localizado na periferia de São Paulo.

Este fato reflete a atração e a repulsão concomitantes de que o hospital historicamente fora objeto, e apenas virtualmente podem ser hoje apreendidas. A expansão desigual e não projetada sofrida principalmente pelas metrópoles obscureceu essa tendência, tornando difícil sua percepção, posto que os hospitais aparecem espalhados em todo o espaço urbano. O Hospital Emílio Ribas, no valorizado bairro de Cerqueira César, atesta essa inversão de registros, e nos auxilia a visualizá-la. Inaugurado a 8 de janeiro de 1880, o antigo Hośpital de Isolamento de São Paulo tivera sua construção iniciada quatro anos antes por subscrição pública promovida pela Câmara Municipal. Convencido da necessidade de segregar os focos de infecção para evitar a propagação da varíola, então epidêmica na Capital, o Governo da Província destinara uma verba que cobriria também as despesas de desapropriação do terreno situado à Estrada do Araçá (a atual Av. Dr. Arnaldo), no 1. Para se ter uma idéia de quão descampada era, na época, essa região, basta lembrar que apenas em 1896 foi, ali mesmo, instalado o Cemitério do Araçá, como complemento ao Cemitério da Consolação, fundado em 1854, e de cuja expansão também podemos derivar o sentido do crescimento urbano. 
Ao diferenciar nas pessoas o ser político de seu corpo biológico, o hospital assesta um dos limites da definição de cidadania, e se institui enquanto espaço fronteiriço ao direito de seu pleno exercício. A condição de exterioridade do hospital em relação à vida social pode ou, ao menos, pôde ser também caracterizada a partir do ponto de vista da geografia do traçado urbano. A primeira tarefa do pesquisador da nova disciplina será, portanto, reconstituir a história da cidade através do estudo retrospectivo de seus hospitais.

A mesma relação de exterioridade e o mesmo jogo de proximidades e distâncias, de alheamento e integração, podem ser identificados num segundo estudo geográfico abordando agora a divisão de espaços no interior do hospital. A lógica médica que ordena o ambiente hospitalar impõe uma série de barreias e acessos diferenciais, dirigindo o fluxo de todos que ali adentram. Alguns preceitos da divisão funcional dos blocos e andares que compõem um hospital são transparentes e, pode-se mesmo dizer, louváveis. Tentam, por exemplo, afastar ao máximo os locais como as salas cirúrgicas e os berçários, onde a susceptibilidade a infecções é mais acentuada, das seções que assistem aos portadores de moléstias contagiosas. Em outros casos, no entanto, o mesmo não poderia ser dito. Os subterfúgios empregados para ocultar a trajetória que precisam fazer os mortos percorrer, e a preocupação em dispor as salas de velório em locais de acesso separado, são exemplos de como as razões médicas podem reforçar os estigmas sociais.

A centralização do poder de definição do espaço interno dos hospitais, e da rotina de seu funcionamento, coincide com a centralização das decisões clínicas e terapêuticas na figura do médico, respaldadas ambas por sua titulação acadêmica. Esse fato estabelece o topo de uma hierarquia à qual se agregam as demais categorias profissionais que atuam no hospital, e cuja forma de relacionamento mútuo, a disciplina, é fator de constantes ressentimentos e tensões que se repassam preferencialmente a seus mais baixos escalões, chegando inúmeras vezes a repercutir nos pacientes, em suas visitas e em seus acompanhantes. É comum funcionários sem maiores habilitações terapêuticas erigiremse em pequenos ditadores que suscitam o pavor de doentes e familiares aflitos.

Situada na intersecção do hospital com a cidade, a portaria delimita seu ambiente interno com o entorno social, e não apenas do ponto de vista espacial. Ali os pacientes são triados e encaminhados às unidades de pronto-atendimento, à internação ou ao ambulatório. Ali são preenchidos os papéis necessários à efetivação do ato médico. Ali são prestadas as contas dos serviços prestados, e se procura acertá-las. A portaria é um lugar tão importante, que há quem a chame de "coração" do hospital. Em muitos hospitais, os médicos plantonistas costumam inclusive revezar-se na função de porteiro para evitar triagens excessivamente invasivas realizadas por funcionários sem qualificação clínica. 
Do ponto de vista do hospital, a portaria representa um primeiro teste a respeito da aceitação dos pacientes quanto às normas da casa. Daí sua eminente conotação simbólica: desse teste se deduz a possibilidade de efetivar a bom termo todas as etapas do ato médico. Do ponto de vista do paciente, entretanto, o relevo da portaria reside no fato de ela marcar, para ele, o princípio de sua desventura hospitalar. Como se já não tivesse bastante preocupações, é também ali que ele começa a enfrentar os tiranetes vestidos de branco.

Um outro ponto de intersecção do hospital com a vida social pode ser percebido, por quem está ali dentro, nas próprias janelas do hospital. Uma pesquisa inaudita realizada no Hospital de Yale - New Haven, e relatada por John D. Thompson e Grace Goldin, em seu The Hospital: A Social and Architectural History (New Haven, Yale University Press, 1975), perguntara aos pacientes o que mais lhes agradava no hospital em que estavam internados. A resposta fora quase unânime entre homens e mulheres de todas as classes sociais, e em todas as seções clínicas: "as janelas". Apreciavam olhar pela janela, e revelavam passar bastante tempo fazendo-o. Uma mulher disse que a janela comunicava o quarto com o exterior, e a fazia sentir-se menos prisioneira.

O Hospital Israelita Albert Einstein, em São Paulo, descobriu empiricamente a importância da janela para seus internos: os quartos com visão para o bairro do Morumbi sempre lotam antes, de modo espontâneo, que a fachada oposta. Também ciente disso, o Hospital Osvaldo Cruz oferece dois tipos de acomodações a seus pacientes. Ambos são apartamentos individuais servidos por todas as regalias de um hotel cinco estrelas. A única diferença entre eles é a existência de um terraço dando para um belíssimo jardim central nos quartos cuja diária é mais elevada. Além de consolidar as estratégias de marketing do hospital, e ampliar sua captação de recursos, sua administração cultiva o jardim como fator de incremento da eficácia terapêutica da instituição médica. O Hospital Emílio Ribas talvez não estivera atento a essa questão no passado, e hoje indaga as consequências de sua fachada, quase de frente a um grande cemitério, sobre os pacientes.

Sejam os passarinhos, seja a confusão no tráfego ou o paulatino desenvolvimento de uma construção civil, o paciente que olha para a janela vê aquilo que não existe no hospital. Quando vista de longe, apenas consegue identificar sua moldura. Mesmo assim a janela the faz lembrar sua liberdade e autonomia, conseguidas a duras penas, e que lhe foram suprimidas na internação. Por menores que elas possam ser nas sociedades contemporâneas, onde variam segundo a posição social de seus integrantes, são sem dúvida ainda menores no interior de um hospital.

A segunda tarefa do cientista da nova disciplina será, então, levar adiante o projeto de esmiuçar, do ponto de vista humano, o ambiente interno de cada hospital estudado. A história de constituição deste ambiente. Sua organização setorial. A divisão funcional de seus blocos e andares. O fluxo diferencial das diversas correntes migrató- 
rias em seu interior: a verdadeira peregrinação dos pacientes, os caminhos percorridos pelas várias categorias profissionais que ali atuam, a trajetória da roupa suja, do material descartado, etc. Os arredores do hospital. O desfile das desgraças que começa em suas calçadas, e pode ser sentido no cenho franzido das pessoas sentadas nas salas de espera. Estes, dentre outros poderiam ser alguns dos temas de interesse da nova disciplina.

O principal conceito da nova disciplina (a exterioridade do hospital à vida social) e seus corolários (a atração e a repulsão concomitantes que exerce sobre os cidadãos) deverão ser integrados também a uma terceira e última tarefa a ser apresentada aos novos cientistas. Sob a legenda de uma filosofia da ciência, eles deverão conjugar a teoria que elaboram sobre o hospital a uma teoria sobre a sociedade que o institui.

Os médicos atribuem a manutenção e a proliferação de hospitais, um privilégio oneroso, a uma contribuição positiva que eles exercem sobre a vida social. Em outras palavras, dizem que os hospitais existem para cumprir necessidades que a sociedade, de outro modo, não poderia contemplar. Em vez de reforçar a base teórica sobre a qual se assentam os hospitais, esta proposição deveria prestar-se a uma crítica social, visto que se a sociedade precisa do hospital para existir é por ser, desde logo, uma sociedade doente.

Apesar de terem formas variando do individual (cura, fuga à dor, reabilitação) ao coletivo (profilaxia, higiene, saúde pública), as necessidades que o hospital procura satisfazer são representações sociais das próprias carências instituídas pela vida urbana. Uma configuração social competitiva e positivamente orientada exclui diversas dimensões da existência para além das fronteiras que delimitam sua identidade. Uma sociabilidade que não comporta a dor e o sofrimento, a imanência da morte, a fragilidade biológica - dimensões que coexistem com a alegria, a capacidade produtiva e a prodigalidade biológica - não pode cuidar de seus enfermos, nem tampouco promover a saúde coletiva, e para isso recorre às instituições médicas.

Uma sociabilidade que não suporta a tristeza, a infelicidade e o fracasso que muitas vezes ela mesma provoca, precisa construir espaços de supressão de si própria para onde possa deportar quem lhe desvia a atenção para aquilo que já fora excluído de sua identidade. Neste sentido, não a doença em si, mas seu reconhecimento institucional é um dos passaportes que habilitam algumas pessoas, em alguns momentos, numa seleção imponderável, à exclusão social.

O hospital é então, uma das bordas da cidade, onde a vida social entra em regime de suspensão. Lugar da dor, da ausência, lugar da restrição de possibilidades. Em tais 

Paulo, 1(1): 227-234, 1.sem. 1989.

lugares se evidenciam os limites físicos da existência humana. A fronteira da intimidade recua para dentro da própria pele, deixando-a desprotegida. Já não se é senhor de seu próprio corpo, e é muito se ao menos o coração se pode manter incólume. A existência de hospitais é duplamente triste. Por um lado eles presenciam condições desprivilegiadas de vida e a morte. E, por outro, atestam a insensibilidade de uma forma de vida em comum que para manter-se necessitou erradicar os desafortunados.

\footnotetext{
ANTUNES, José Leopoldo Ferreira. Towards a hospital geography. Tempo Social; Rev. Sociol. USP Săo Paulo, 1(1): 227-234, 1.sem. 1989.
}

ABSTRACT: The article's aim is to introduce "hospital geography" as a new discipline in the field of social sciences, focused on medical institutions and professional health proceedings. Its bases are summarily established and its object is defined by means of three research areas: retrospective studies of hospital insertion in urban space, examinations of hospital internal divisions, both with regard to space and to the migratory flow of people, and discussion of the relationship between hospital and society. Under the pretense of presenting some parameters for the establishment of an unprecedented discipline, this study tries to emphasize a non-conventional approach to hospital leading to a criticism of medical institutions, even if only by means of a few directions for empirical research.

UNITERMS: Health institutions, hospital and urbanism, hospital and society. 